\title{
CONSEQUENCES TO FLOOD MANAGEMENT OF USING DIFFERENT PROBABILITY DISTRIBUTIONS TO ESTIMATE EXTREME RAINFALL
}

\author{
Luciana S. Esteves ${ }^{1}$
}

Cities Institute, London Metropolitan Business School, London Metropolitan University Stapleton House, 277-281 Holloway Road, London N7 8HN, UK

l.slompesteves@londonmet.ac.uk

\section{ABSTRACT}

The design of flood defences, such as pumping stations, takes into consideration the predicted return periods of extreme precipitation depths. Most commonly these are estimated by fitting the Generalised Extreme Value (GEV) or the Generalised Pareto (GP) probability distributions to the annual maxima series or to the partial duration series. In this paper, annual maxima series of precipitation depths obtained from daily rainfall data measured at three selected stations in southeast UK are analysed using a range of probability distributions. These analyses demonstrate that GEV or GP distributions do not always provide the best fit to the data, and that extreme rainfall estimates for long return periods (e.g. 1 in 100 years) can differ by more than 40\% depending on the distribution model used. Since a large number of properties in the UK and elsewhere currently benefit from flood defences designed using the GEV or GP probability distributions, the results from this study question whether the level of protection they offer are appropriate in locations where data demonstrate clearly that alternative probability distributions may have a better fit to the local rainfall data. This work: (a) raises awareness of the limitations of common practices in extreme rainfall analysis; (b) suggests a simple way forward to incorporate uncertainties that is easily applicable to local rainfall data worldwide; and thus (c) contributes to improve flood risk management.

KEYWORDS: extreme rainfall; probability distribution; return period; flood defence; risk management

\footnotetext{
${ }^{1}$ Current affiliation: School of Applied Sciences, Bournemouth University, UK lesteves@bournemouth.ac.uk
} 


\section{Introduction}

Flooding is the most frequent and damaging natural hazard worldwide, which affected 178 million people and caused losses that exceeded US $\$ 40$ billion (about £25.32 billion) in 2010 (Jha et al., 2012). The mortality risk associated with major floods and storms has declined globally in the last two decades; however, the exposure of people and economic assets to natural hazards is rapidly increasing, especially in developed countries (UNISDR, 2011). In the UK, for example, about 2.05 million properties were estimated to be at risk from flooding in 2004 (Evans et al., 2004). More recently the Environment Agency (EA, 2009) estimated that 5.2 million properties were at risk from flooding in England alone. Of these, 3.8 million properties are at risk from flooding from surface runoff ( $E A, 2011)$. Despite differences in the methodology used in the two assessments, it is clear that flood risk in England (and worldwide) is becoming a much larger threat than previously anticipated. Climate change and poor urban planning are likely to increase flood risk in the future; the first by affecting local rainfall patterns and enhancing storminess; and the latter for placing people and critical infrastructure in flood-prone areas. Despite the implementation of policies regulating occupation of flood risk areas, planning systems often favour development needs above the need to reduce flood risk (e.g. White and Howe, 2002; Wheather and Evans, 2009; Jha et al., 2012). In the last two years, extreme rainfall caused devastating floods in developing and developed countries across all continents (e.g. Australia, Pakistan, Philippines, Thailand, South Africa, Brazil, France, the UK and the USA).

Uncertainties are inherent in the prediction of the frequency and extent of all types of flood. However, flooding from some sources can be better predicted than others. Coastal flooding is a serious threat at many locations, and a network of flood defences is usually in place to provide protection from water levels of specific return periods. The cyclic nature of tides facilitates the prediction of extreme water levels, which occur when storm surges coincide with high spring tides. Despite some uncertainties related to the prediction of storm surges, extreme water levels can be modelled with reasonable results (e.g. Pugh, 1996; Flather et al., 1998; Verlaan et al., 2005; Brown et al., 2010). Additional uncertainties arise when the impacts of climate change are included in the predictions of return periods of extreme sea levels (e.g. Lowe and Gregory, 2005; Wang et al., 2008).

Flooding caused by other processes is more difficult to predict (and mitigate) due to the number of influencing variables and their complex relationships. For example, extreme rainfall can lead to flooding from overwhelmed rivers and sewers. This is very difficult to predict (Wheater and Evans, 2009), especially at meaningful time-scales for adequate response. Further complexity is added by urbanisation, particularly by the increase in 
impervious surfaces and obsolete combined sewer/stormwater drain systems (Thurston et al., 2010). Many locations have systems of pumps and water storage to prevent floods from surface runoff and/or overwhelmed drains (Wheater and Evans, 2009). However, the efficiency of these systems depends on their (flow/volume) capacity, which is designed to deal with rainfall of specific return period (e.g. 1 in 100 years). To provide the desired level of protection, it is imperative that the precipitation depths used to design flood defences are estimated taking into consideration uncertainties related to the method and to the potential changes in rainfall patterns and trends caused by climate change.

At many locations worldwide, flood defences at the coast and in urban areas are in urgent need of upgrading to cope with the effects of urban development and predicted impacts of climate change (e.g. higher sea levels and more frequent and intense extreme rainfall). Return periods of extreme rainfall are usually estimated by fitting a probability distribution (PD) to annual maxima series (i.e. datasets comprised by the highest rainfall depth in each year) or partial duration series (i.e. datasets formed by rainfall depths exceeding a selected threshold) (e.g. Cunnane, 1973; Rosbjerg, 1977; Davidson and Smith, 1990; Adamowski, 2000). The most common PD used in the analysis of extreme rainfall are the Generalised Extreme Value (GEV) or the Generalised Pareto (e.g. Davidson and Smith, 1990; Coles, 2001; Bodini and Cossu, 2010; Toretti et al., 2010). However, other PDs might show a better fit to some datasets and the difference in the precipitation depths for the resulting return periods can be significant. Adequate selection of the PD is one of the "more important issues in flood frequency analysis" (Adamowski, 2000, p. 220).

This article draws attention to the limitations of the common approach used in extreme rainfall analyses and discusses the potential consequences for the design of flood defences and the level of protection they offer. The influence of using different PDs in estimating extreme rainfall is demonstrated using, as examples, three selected locations in southeast England. A simple way forward to incorporate uncertainties in the estimates of rainfall depths of return periods relevant to flood risk management is then suggested. The findings of this study will assist local authorities responsible for flood management in improving decisionmaking concerning mitigation of flood risk.

\section{Methods}

Time-series of daily rainfall measurements were obtained from the Met Office MIDAS Land Surface Stations ${ }^{2}$. The data analysis was conducted as part of the EU-funded project Solutions for Environmental Contrasts in Coastal Areas (SECOA). The stations analysed

\footnotetext{
${ }^{2}$ http://badc.nerc.ac.uk/view/badc.nerc.ac.uk_ATOM_dataent_ukmo-midas
} 
here were selected to assess the magnitude and frequency of extreme rainfall in Portsmouth and the Thames Gateway, the project's study areas in the UK. For the area of Portsmouth, the Southsea station was selected due to the length of the daily rainfall record. Two locations were selected in the Thames Gateway: Southend in the eastern sector of the study area and Deptford in the western sector. Table 1 shows the characteristics of the datasets used here in the analysis of extreme rainfall. Data from two closely located stations were used to extend the time-series at Southend.

Table 1. Summary of the Met Office MIDAS datasets of daily rainfall used in this study.

\begin{tabular}{|c|c|c|c|c|}
\hline Station name (code) & Coordinates ${ }^{\mathrm{a}}(\mathrm{m})$ & Period & $\mathrm{n}$ & Observations \\
\hline $\begin{array}{l}\text { Southsea } \\
\text { (src_id 861) }\end{array}$ & $\begin{array}{l}\text { 463700, } 99100 \\
\text { (Hampshire) }\end{array}$ & $01 / 01 / 1916$ to $30 / 06 / 1997$ & $\begin{array}{l}29299 \text { days } \\
966 \text { months } \\
81 \text { years }\end{array}$ & $\begin{array}{l}\text { Elevation: } 2 \mathrm{~m} \\
\text { Drainage: coastal }\end{array}$ \\
\hline $\begin{array}{l}\text { Southend } \\
\text { (src_id 492) }\end{array}$ & 587600,185200 & $24 / 01 / 1961$ to $01 / 01 / 1971$ & 12721 days & Elevation: $27 \mathrm{~m}$ \\
\hline $\begin{array}{l}\text { Southend } \\
\text { Southchurch Park } \\
\text { (src_id 496) }\end{array}$ & $\begin{array}{l}\text { 589986, } 184998 \\
\text { (Essex) }\end{array}$ & $\begin{array}{l}\text { 01/01/1971 to 01/10/2010 } \\
\text { (major data gaps 01/1977- } \\
\text { 02/1986, 09/2005-08/2008) }\end{array}$ & $\begin{array}{l}419 \text { months } \\
39 \text { years }\end{array}$ & $\begin{array}{l}\text { Elevation: } 4 \mathrm{~m} \\
\text { Drainage: coastal }\end{array}$ \\
\hline $\begin{array}{l}\text { Deptford P Sta } \\
\text { (src_id 6704) }\end{array}$ & $\begin{array}{l}537600,177000 \\
\text { (Greater London) }\end{array}$ & $\begin{array}{l}24 / 01 / 1961 \text { to } 31 / 12 / 2010 \\
\text { (data gap } 02 / 1999-02 / 2000 \text { ) }\end{array}$ & $\begin{array}{l}11969 \text { days } \\
580 \text { months } \\
49 \text { years }\end{array}$ & $\begin{array}{l}\text { Elevation: } 5 \mathrm{~m} \\
\text { Drainage: } \\
\text { Ravensbourne }\end{array}$ \\
\hline
\end{tabular}

${ }^{\mathrm{a}}$ Coordinates are provided in the British National Grid system.

Annual maxima series (AMS) for 1-day, 2-day and 3-day durations were produced from the daily rainfall time-series at the three locations. Maxima series for winter (WMS) and summer (SMS) precipitation were also produced for 1-day, 2-day and 3-day durations. The WMS were based on records from December, January and February months and the SMS were based on data recorded in June, July and August. The precipitation depths for selected return periods were estimated by fitting PDs to the AMS, WMS and SMS datasets for the three durations. Six PDs were tested: Generalised Extreme Value (GEV), lognormal (LN), Gumbell Maximum (EV1), Log-Pearson III (LP3), Weibull and Burr. Description of these distributions can be found on a wide range of publications on statistical distributions (e.g. Johnson et al., 1994; Forbes et al., 2011) or in focused articles (e.g. Burr, 1942; Tadikamalla, 1980). The goodness-of-fit was measured using the Kolmogorov-Smirnov (K-S) and the Anderson-Darling (A-D) tests. Additionally, the software EasyFit3 was used to find

\footnotetext{
${ }^{3}$ http://www.mathwave.com/products/easyfit.html
} 
the best-fit distribution to the datasets. Precipitation depths for selected return periods were then estimated based on the best-fit probability distributions.

\subsection{Kolmogorov-Smirnov Test (K-S)}

This test is used to decide if a sample comes from a population with a specific distribution (NIST/SEMATECH, 2010). For a detailed description of the test see Chakravarti et al. (1967). It is based on the empirical cumulative distribution function denoted by

$F n(x)=\frac{1}{n}[$ Number of observations $\leq x]$

The Kolmogorov-Smirnov statistic (D) is based on the largest vertical difference between the theoretical and the empirical cumulative distribution function:

$D=\max _{1 \leq i \leq n}\left(F\left(x_{i}\right)-\frac{i-1}{n}, \frac{i}{n}-F\left(x_{i}\right)\right)$

The null hypothesis (Ho: the data follow the specified distribution) is rejected at the chosen significance level (here $\alpha=0.01$ ) if $D$ is greater than the critical value obtained from a table. The P-value is calculated based on the test statistic, and denotes the threshold value of the significance level in the sense that the null hypothesis will be accepted for all values of $\alpha<P$. For example, if $P=0.025$, the null hypothesis will be accepted at all significance levels less than $P(\alpha<0.025)$ and rejected at higher levels (e.g. $\alpha=0.05)$.

\subsection{Anderson-Darling Test (A-D)}

This is a modification of the K-S test that gives comparatively more weight to the tails than the centre of the distribution (NIST/SEMATECH, 2010). The A-D test has been used as an alternative to the K-S and Chi-square goodness-of-fit tests. For detailed explanation of the A-D test see Anderson and Darling $(1952,1954)$ or Stephens $(1974,1977)$. The A-D statistic $\left(A^{2}\right)$ is defined as

$$
A^{2}=-n-\frac{1}{n} \sum_{i-1}^{n}(2 i-1)\left[\ln F(X i)+\ln \left(1-F\left(X_{n-i+1}\right)\right)\right]
$$


The null hypothesis (Ho: the data follow the specified distribution) is rejected at the chosen significance level $(\alpha)$ if $\mathrm{A} 2$ is greater than the critical value (which in Easyfit is dependent on the sample size).

\section{Results}

Although it is out of the scope of this article to characterise the annual and seasonal rainfall at the three locations, a statistical summary of the datasets analysed here is shown in Table 2. The highest annual 1-day precipitation was observed in Southend on 16 September 1968, when $79.5 \mathrm{~mm}$ of rain was measured. In Deptford and Southsea, the highest annual 1day precipitation was $71 \mathrm{~mm}$ on 21 September 1973 and $61.3 \mathrm{~mm}$ on 15 September 1927, respectively. The highest winter and summer 1-day precipitation were measured in Southsea, $51 \mathrm{~mm}$ on 8 December 1937 and $59.1 \mathrm{~mm}$ on 7 August 1956, respectively. The highest 2- and 3-day precipitation reached $110.50 \mathrm{~mm}$ and $121.40 \mathrm{~mm}$, respectively (Table 2), both starting on 15 September 1968 and recorded in Deptford. Note that this is the same rainfall event that caused the 1-day highest precipitation in Southend, located about $55 \mathrm{~km}$ east of Deptford.

Generally, the summer shows higher mean and maximum precipitation depths than the winter and the highest annual maxima do not occur in the winter or summer (Table 2). In Southsea, the differences between the annual, winter and summer maximum precipitation are considerably smaller than the differences observed at the other stations. The largest differences occur between the annual and winter maximum values, which range from $16 \%$ to $26 \%$ in Southsea, from $50 \%$ to $57 \%$ in Deptford and from $58 \%$ to $65 \%$ in Southend. The largest differences between the winter and summer maximum values are observed for the 1day durations, which are particularly pronounced in the Thames Gateway stations (39\%). Southsea shows the highest maximum precipitation in the winter and summer, but annual maximum values (23\% to $35 \%$ ) lower than at the other stations. In the summer, differences between all stations are small (a maximum of $12 \%$ difference is observed for 1 -day duration between Southsea and Deptford) when compared with the differences in winter (a maximum of $38 \%$ is observed for 1 -day duration between Southsea and Deptford). 
Table 2. Statistical summary for annual, winter and summer maximum precipitation for 1,2 and 3-day durations at Southend, Deptford and Southsea.

\begin{tabular}{|c|c|c|c|c|c|c|}
\hline & & $\mathrm{n}$ & Min & Mean & Max & St Dev \\
\hline \multirow{9}{*}{ 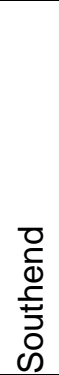 } & Annual 1-day & 39 & 14.0 & 30.97 & 79.5 & 13.89 \\
\hline & Annual 2-day & 39 & 19.9 & 38.56 & 109.2 & 16.41 \\
\hline & Annual 3-day & 39 & 24.1 & 43.98 & 116.1 & 16.83 \\
\hline & Winter 1-day & 36 & 4.6 & 15.03 & 31.6 & 7.75 \\
\hline & Winter 2-day & 36 & 5.6 & 18.61 & 37.2 & 9.27 \\
\hline & Winter 3-day & 36 & 6.0 & 22.31 & 48.2 & 11.52 \\
\hline & Summer 1-day & 36 & 6.4 & 21.82 & 52.0 & 11.38 \\
\hline & Summer 2-day & 36 & 7.8 & 26.21 & 58.2 & 12.65 \\
\hline & Summer 3-day & 36 & 11.2 & 30.02 & 63.8 & 14.03 \\
\hline \multirow{9}{*}{$\begin{array}{l}\frac{0}{0} \\
\text { D } \\
0 \\
0\end{array}$} & Annual 1-day & 49 & 14.0 & 31.88 & 71.0 & 11.32 \\
\hline & Annual 2-day & 49 & 20.1 & 41.28 & 110.5 & 14.67 \\
\hline & Annual 3-day & 49 & 24.4 & 46.19 & 121.4 & 15.76 \\
\hline & Winter 1-day & 48 & 7.1 & 16.11 & 35.4 & 6.58 \\
\hline & Winter 2-day & 48 & 10.4 & 20.75 & 47.4 & 7.66 \\
\hline & Winter 3-day & 48 & 10.7 & 24.92 & 58.2 & 9.92 \\
\hline & Summer 1-day & 49 & 8.0 & 23.42 & 57.6 & 10.61 \\
\hline & Summer 2-day & 49 & 8.2 & 28.35 & 60.8 & 12.36 \\
\hline & Summer 3-day & 49 & 9.6 & 31.62 & 62.5 & 12.96 \\
\hline \multirow{9}{*}{ 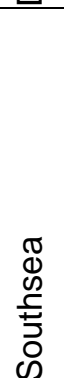 } & Annual 1-day & 81 & 14.8 & 33.39 & 61.3 & 10.03 \\
\hline & Annual 2-day & 81 & 19.0 & 41.89 & 72.2 & 10.42 \\
\hline & Annual 3-day & 81 & 22.0 & 49.60 & 87.4 & 12.17 \\
\hline & Winter 1-day & 76 & 7.7 & 22.82 & 51.0 & 8.69 \\
\hline & Winter 2-day & 76 & 7.8 & 31.01 & 56.4 & 10.11 \\
\hline & Winter 3-day & 76 & 11.5 & 38.34 & 64.4 & 11.50 \\
\hline & Summer 1-day & 76 & 8.1 & 24.81 & 59.1 & 10.72 \\
\hline & Summer 2-day & 76 & 9.2 & 30.05 & 64.8 & 11.89 \\
\hline & Summer 3-day & 76 & 10.8 & 33.38 & 67.6 & 13.01 \\
\hline
\end{tabular}

\subsection{Goodness-of-fit tests}

Table 3 shows the K-S and A-D statistics indicating the goodness-of-fit of the six probability distributions tested to model the AMS, WMS and SMS datasets. The best results for each dataset are highlighted in bold, with squares indicating the cases in which both tests have identified the same distribution as the best fit (i.e. in five AMS, four WMS and eight SMS). The Weibull distribution showed the worst results in both K-S and A-D tests for the annual datasets, while the lognormal (LN) distribution performed poorly for the winter and summer datasets (Table 3). The Burr distribution showed the best overall result, being the best fit for 15 and 14 series based on the K-S and the A-D tests, respectively. The Burr distribution performs particularly well for the summer series. However, further analysis indicates that improved fit could be provided by other distributions for some of the datasets. Parameter values for the Burr and best-fitted distributions for the AMS are shown in the Appendix A. 
The K-S and A-D tests have identified the same distribution as the best fit only for eight datasets: Southend WMS 1 and 2-day durations; Deptford AMS 1, 2 and 3-day durations; Southsea WMS 3-day duration and SMS 2 and 3-day durations. In half of these datasets, the Burr distribution was found to be the best fit. In total, the Burr distribution showed the best fit nine times according to the K-S test and six according to the A-D test, being the bestfit distribution to the largest number of datasets. However, in addition to the Burr, a further 17 distributions were identified as the best fit by either the K-S or A-D tests. The second most common best fit was provided by the Dagum distribution (also known as the Burr Type 3 or inverse Burr), appearing twice in the K-S results and seven times in the A-D. The third distribution best fitting the datasets was the GEV, once in the K-S test and five times in the A-D. There was no pattern of specific distributions fitting better datasets of specific locations, durations or maxima series.

Table 3. Results of the Kolmogorov-Smirnov (K-S) and Anderson-Darling (A-D) goodness-of-fit tests for the six probability distributions tested.

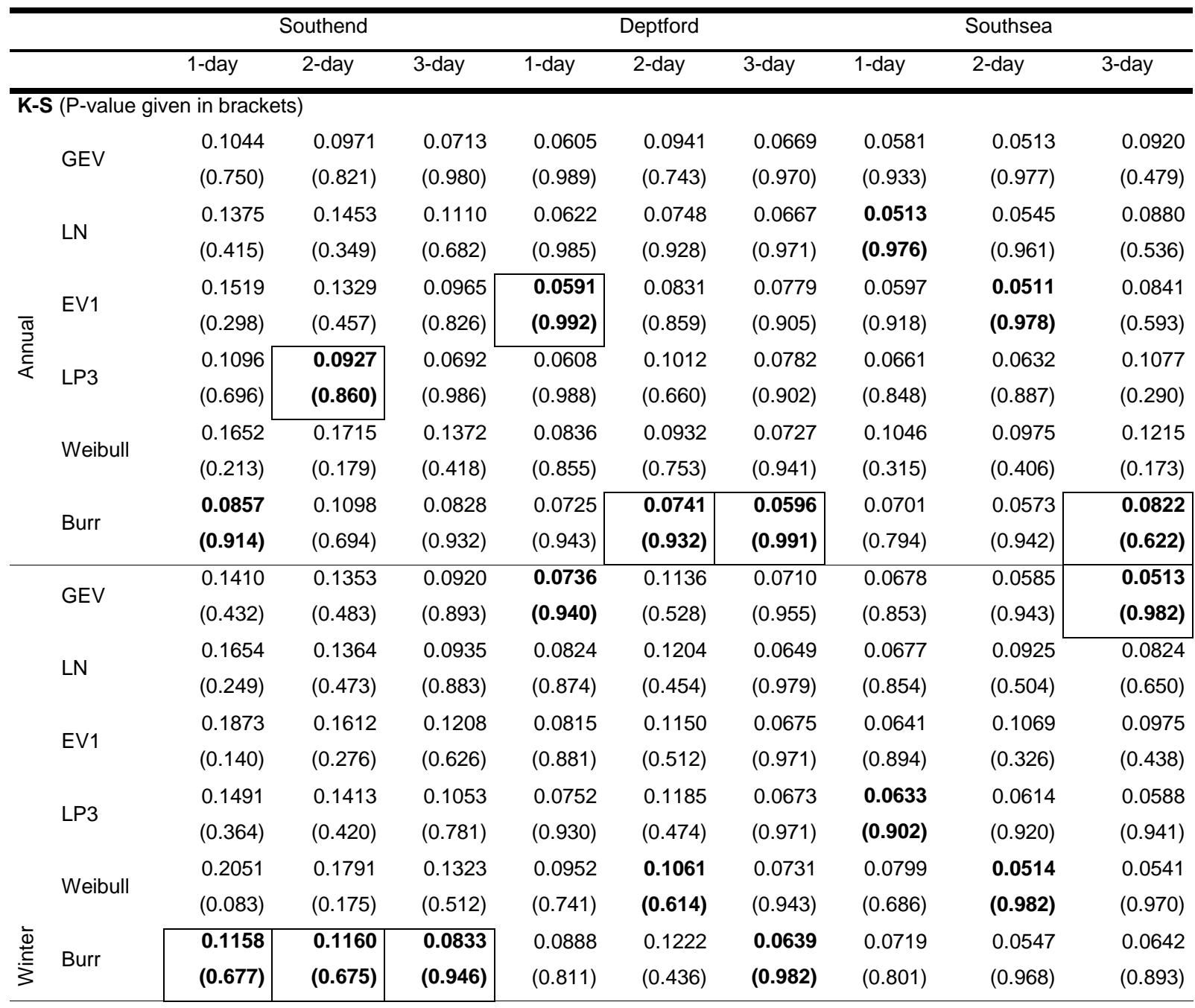


Journal of Environmental Management, 30 January 2013, Volume 115, 98-105.

\begin{tabular}{|c|c|c|c|c|c|c|c|c|c|c|}
\hline & GEY & 0.0817 & 0.1006 & 0.0829 & 0.0978 & 0.0741 & 0.0602 & 0.0483 & 0.0760 & 0.0422 \\
\hline & ULV & $(0.954)$ & $(0.824)$ & $(0.948)$ & $(0.670)$ & $(0.932)$ & $(0.990)$ & $(0.991)$ & $(0.743)$ & (0.998) \\
\hline & $\mathrm{N}$ & 0.0907 & 0.1064 & 0.0838 & 0.1024 & 0.0976 & 0.1142 & 0.0565 & 0.0941 & 0.0808 \\
\hline & LIV & $(0.902)$ & $(0.771)$ & $(0.944)$ & $(0.645)$ & $(0.702)$ & $(0.509)$ & (0.957) & $(0.483)$ & $(0.674)$ \\
\hline & EVy1 & 0.1176 & 0.1270 & 0.1002 & 0.0884 & 0.0747 & 0.0874 & 0.0465 & 0.0733 & 0.0739 \\
\hline & EVI 1 & (0.659) & $(0.560)$ & $(0.828)$ & $(0.806)$ & (0.929) & $(0.816)$ & (0.994) & $(0.782)$ & $(0.773)$ \\
\hline & $P_{2}$ & 0.0948 & 0.1076 & 0.0811 & 0.0985 & 0.0724 & 0.0713 & 0.0519 & 0.088 & 0.048 \\
\hline & LFo & $(0.873)$ & $(0.759)$ & $(0.956)$ & $(0.691)$ & $(0.943)$ & $(0.950)$ & $(0.981)$ & $(0.565)$ & (0.991) \\
\hline & & 0.1246 & 0.1427 & 0.1044 & 0.1082 & 0.0662 & 0.0701 & 0.0757 & 0.0954 & 0.0452 \\
\hline & vvetioum & $(0.588)$ & $(0.417)$ & $(0.790)$ & $(0.578)$ & $(0.973)$ & $(0.956)$ & $(0.747)$ & $(0.465)$ & (0.996) \\
\hline$\stackrel{\text { है }}{\xi}$ & Purr & 0.0795 & 0.0981 & 0.0933 & 0.0982 & 0.0603 & 0.0555 & 0.0375 & 0.0699 & 0.0391 \\
\hline के & Burr & $(0.963)$ & $(0.846)$ & $(0.884)$ & (0.695) & (0.989) & (0.996) & (0.999) & $(0.826)$ & (0.999) \\
\hline A-I & & & & & & & & & & \\
\hline & GEV & 0.3188 & 0.3230 & 0.2452 & 0.2023 & 0.3086 & 0.3005 & 0.3276 & 0.2631 & 0.3685 \\
\hline & $\mathrm{LN}$ & 0.5080 & 0.6370 & 0.4004 & 0.2006 & 0.3166 & 0.2772 & 0.3425 & 0.2883 & 0.4293 \\
\hline & EV1 & 0.6041 & 0.8663 & 0.5502 & 0.2001 & 0.6043 & 0.5171 & 0.4859 & 0.4044 & 0.6152 \\
\hline & LP3 & 0.3130 & 0.3166 & 0.2481 & 0.2059 & 0.3917 & 0.4107 & 0.3514 & 0.3257 & 0.4473 \\
\hline$\overline{\widetilde{T}}$ & Weibull & 1.5951 & 2.1532 & 1.7600 & 0.8520 & 2.5805 & 2.3729 & 1.1337 & 1.1660 & 1.0863 \\
\hline$\frac{\bar{c}}{<}$ & Burr & 0.3554 & 0.3196 & 2.6082 & 0.2021 & 0.1568 & 0.1795 & 0.4620 & 0.2346 & 0.2731 \\
\hline & GEV & 0.6150 & 0.6989 & 0.3550 & 0.2429 & 0.4512 & 0.2194 & 0.3499 & 0.2270 & 0.1421 \\
\hline & $\mathrm{LN}$ & 0.8102 & 0.7025 & 0.3747 & 0.2621 & 0.4670 & 0.2501 & 0.3630 & 0.7200 & 0.6098 \\
\hline & EV1 & 1.1059 & 0.8680 & 0.4851 & 0.2725 & 0.4463 & 0.2309 & 0.3508 & 1.2317 & 1.1262 \\
\hline & LP3 & 0.6555 & 0.7136 & 0.3939 & 0.2407 & 0.4970 & 0.2402 & 0.3661 & 0.2098 & 0.1490 \\
\hline$\stackrel{\grave{\Phi}}{\leftrightarrows}$ & Weibull & 1.9346 & 1.3903 & 0.8955 & 0.9858 & 0.8302 & 0.6060 & 1.2813 & 0.2410 & 0.2063 \\
\hline $\bar{\xi}$ & Burr & 0.4480 & 0.6157 & 0.3330 & 0.3137 & 0.4786 & 0.2360 & 0.3355 & 0.2308 & 0.2072 \\
\hline & GEV & 0.2820 & 0.4216 & 0.3184 & 0.2814 & 0.1328 & 0.1906 & 1.9897 & 0.5526 & 0.2689 \\
\hline & $\mathrm{LN}$ & 0.3142 & 0.4488 & 0.3136 & 0.2769 & 0.2268 & 0.6303 & 1.8899 & 0.9648 & 0.8387 \\
\hline & EV1 & 0.4352 & 0.5560 & 0.3959 & 0.3058 & 0.1625 & 0.6090 & 1.9809 & 0.7193 & 0.7738 \\
\hline & LP3 & 0.3181 & 0.4472 & 0.2939 & 0.2663 & 0.1441 & 0.2249 & 1.7028 & 0.6540 & 0.3389 \\
\hline 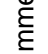 & Weibull & 0.9194 & 1.1613 & 0.7228 & 0.7890 & 0.3765 & 0.2320 & 0.5248 & 0.8568 & 0.3417 \\
\hline के & Burr & 0.2358 & 0.3838 & 0.3877 & 0.3492 & 0.1542 & 0.1849 & 0.8168 & 0.4238 & 0.2219 \\
\hline
\end{tabular}

Bold indicates the best fit for each series; squares indicate cases in which the same best-fit distribution was identified by both tests.

\subsection{Comparing estimated return periods}

The objective here is to quantify the influence of using different distributions to estimate the return periods of extreme rainfall. Therefore, precipitation depths of selected return periods were estimated based on the Burr and best-fit distributions according to the K-S and A-D tests. Appendix B shows the resulting precipitation depths of 5-, 10-, 25-, 50- and 100year return periods for Southend, Deptford and Southsea. Figure 1 illustrates the precipitation depths estimated for up to 1 in 100 years return periods based on the best-fit distributions according to the K-S and A-D tests and the Burr distribution. 


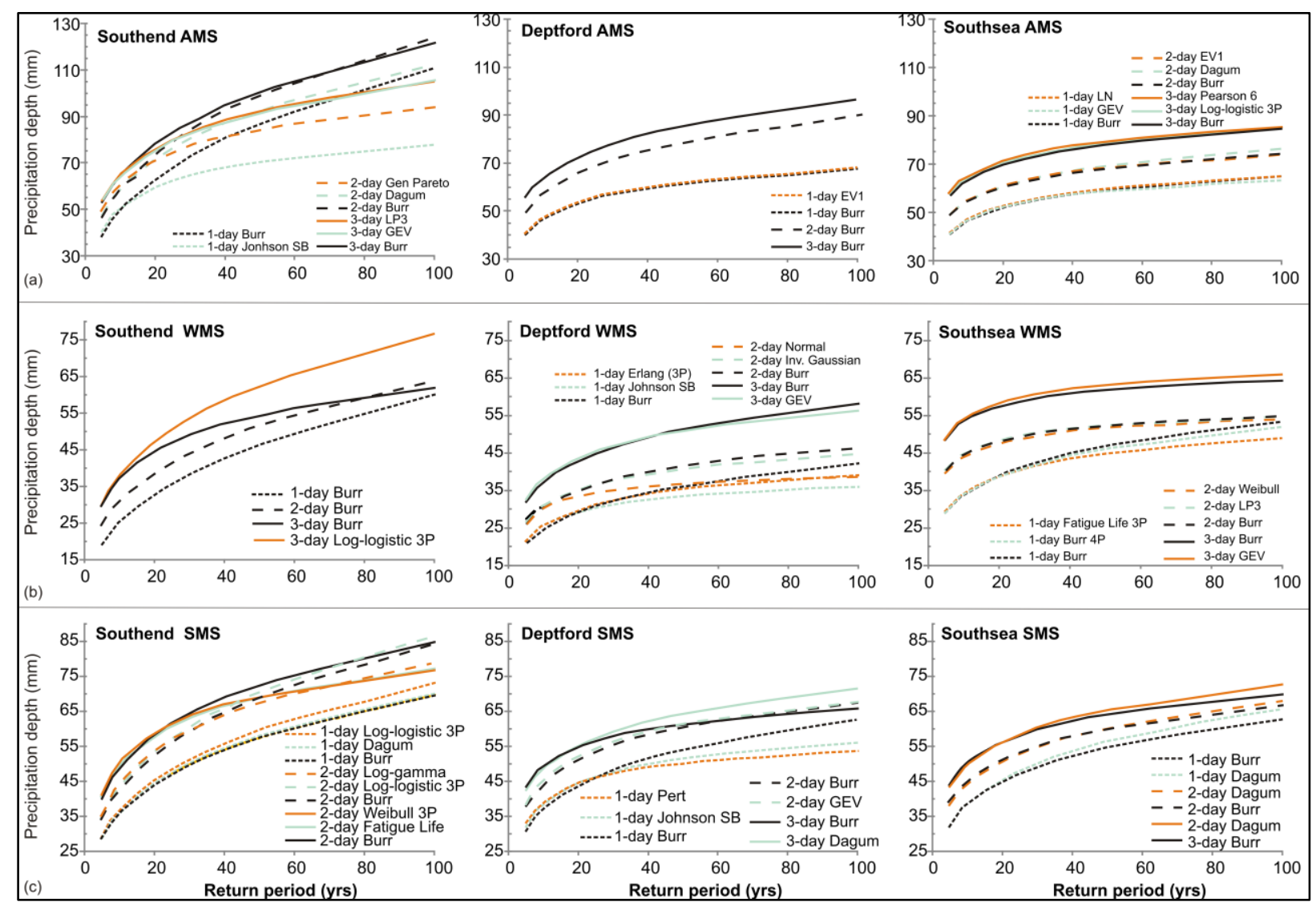

Figure 1. Precipitation depths estimated for up to 1 in 100 years return periods based on the best-fit distributions according to the K-S and A-D tests and the Burr distribution for the AMS (a), WMS (b) and SMS (c) obtained at Southend, Deptford and Southsea.

It is evident that results for some datasets are more consistent (i.e. when both tests indicate the same best-fit distributions or estimates obtained from different distributions were similar), while large differences are observed for others. Generally, differences between estimates of rainfall with return periods shorter than 25 years are less than $8 \%$. Consistent results are found for Deptford and Southsea AMS for 1, 2 and 3-day durations (Figure 1a), where extreme rainfall estimates using the best fit models were smaller than a few millimetres. Therefore, estimates of extreme rainfall even for longer return periods are considered more reliable. A contrasting situation is found for Southend AMS (Figure 2), where the 1 in 100 year rainfall depths for the 1-day duration differ $32.7 \mathrm{~mm}$ or $42 \%$ when estimated by the best-fit distributions according to the K-S or A-D test (i.e. Burr and Johnson $\mathrm{SB}$, respectively). Other datasets, such as Southend and Southsea WMS (Figure 1b), show reliable results for some durations and larger variation for others. For Southend WMS, for instance, both tests indicated the Burr distribution as the best fit for 1 and 2-day durations. However, for the 3-day duration, the best-fit distributions resulted in divergent estimates of rainfall depths for return periods longer than 10 years, reaching a maximum $24 \%$ difference for 1 in 100 year values. For Southsea WMS, the 1-day duration estimates showed divergent results for return periods longer than 30 years. 
Figure 2 shows the largest differences between the estimates of precipitation depths found for the AMS, WMS and SMS at each location and for the 1,2 and 3-day durations. It is evident that differences are larger for the AMS and smaller for SMS with maximum differences found for return periods of 100 years, varying from 15\% (SMS) to $42 \%$ (AMS). Estimates for Southsea appear to show smaller differences (always $<10 \%$ ) when compared with the other two locations. It is also evident that, in some cases, the 1-day duration series show larger differences than the other durations at the same locations (i.e. Southend AMS; Southsea WMS and SMS; and Deptford SMS). Interestingly, differences between the 5-year return period estimates are larger than the 25-year return period for some series, noticeably the 1-day duration estimates for Southend AMS and Deptford WMS and SMS.

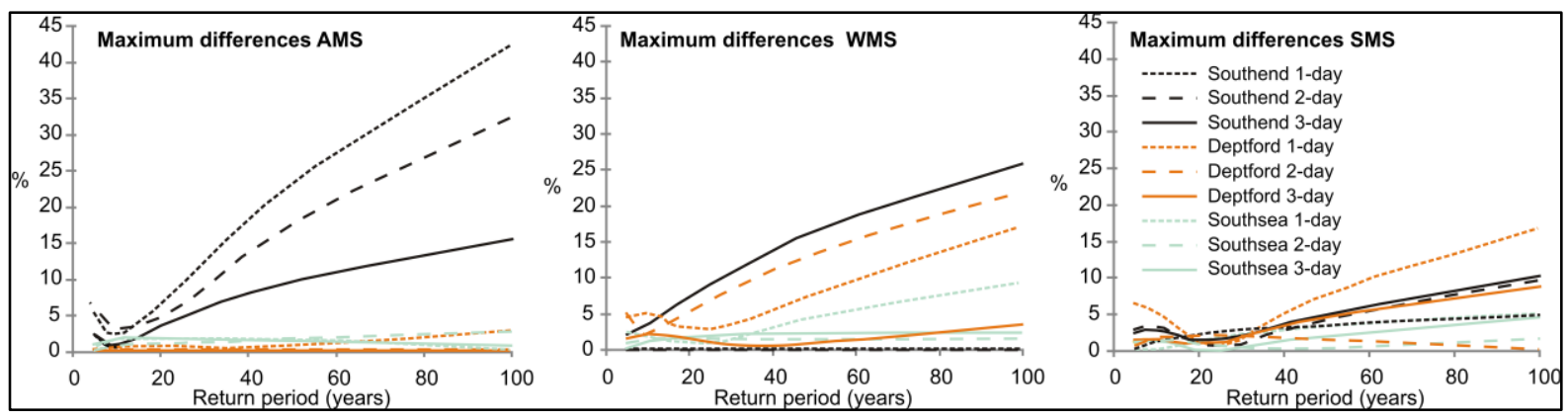

Figure 2. Largest differences between the estimates of precipitation depths found for the AMS, WMS and SMS at Southend, Deptford and Southsea for the 1, 2 and 3-day durations.

\section{Discussion}

This study demonstrates that estimates of extreme rainfall return periods can vary considerably depending on the PD used (see Figure 1). The analysis of rainfall time-series from three locations in southern England has also revealed that the magnitude of differences (i.e. the sensitivity to specific PD) is spatially variable even between stations closely located. In Southsea, for example, differences in estimates of rainfall depths based on best-fit distributions (identified by more than one goodness-of-fit test) are always smaller than 10\% independently on the return period. For the other two locations, differences are smaller than $8 \%$ for return periods of less than 25 years and reach $42 \%$ for a return period of 100 years (at Southend, Figure 2). Previous studies (e.g. the analysis of a long AMS of daily rainfall in Athens by Koutsoyiannis and Baloutsos, 2000) have also acknowledged the limitations of using specific PDs in extreme rainfall analysis. The similarity of findings suggests that the sensitivity to the model used to estimate extreme precipitation is observed in rainfall data recorded in England and elsewhere. It is then probable that the large differences between extreme rainfall estimates obtained for Southend can also be observed in other locations worldwide, making the results of this study widely applicable. 
Results presented here raise concerns about the common practice of using specific PDs in extreme rainfall analysis when other PDs provide a better fit to the data and, consequently, more accurate estimates of return periods relevant to flood risk management. To improve the assessment of the level of protection offered by flood defences, it is necessary to account for the uncertainties inherent to the method of extreme rainfall analysis. The magnitude of the differences in the estimates of extreme rainfall return periods can be used as a measure of uncertainty. Uncertainties in the magnitudes observed in Southend have serious implications for the design of local flood defences. Here, flood defences designed to cope with 1 in 50 years rainfall events based on the best-fit distribution according the K-S test would provide an actual level of protection well above flood defences designed to offer 1 in 100 year level of protection estimated based on the best-fit distribution identified by the A-D test. The large difference between estimates provided by different PDs might explain how flood defences can be overwhelmed by events of return periods (supposedly) within their designed protection level.

Analysis of the flood risk from rivers is usually based on the rainfall over the catchment area and the characteristics of river flow capacity. However, in areas where the topography and/or the limitations of drains/sewage systems indicate a potential for localised flooding from surface runoff due to heavy downpours, better assessment of risk is provided by the analysis of local rainfall measurements. According to Arnaud et al. (2002, p.229), "in most cases design storms do not need to respect the whole rain field, but can be derived from statistics at a given point”. Other studies (e.g. Bodini and Cossu, 2010) also advocate the use of local rainfall data to improve model results, especially at locations where local particularities affect the rainfall distribution over small areas. Properly assessing the capacity of flood defences is key to ensure that they will not be overwhelmed by extreme rainfall events. Therefore, it is advocated here that the design of local flood defences, such as the capacity of pumping stations, should be based on statistics of local rainfall data calculated using PDs offering the best-fit to the observations. It is also suggested here that the sensitivity of the datasets to the model used is assessed by the application of more than one goodness-of-fit tests (e.g. A-D, K-S and Chi-squared).

Through the use of accessible specialist software, it is now relatively simple to identify the best-fit PD for a given local rainfall dataset and to compare estimates of return periods obtained from a range of PDs. To adopt a conservative approach, the design of flood defences should be defined by the highest rainfall depth estimated for the desired level of protection. Although trend analyses have not yet observed strong evidence of increasing rainfall in Europe (e.g. Bodini and Cossu, 2010; Toretti et al., 2010; Norrant and Douguédroit, 2006; Klein Tank and Können, 2003), enhanced extreme rainfall events are 
anticipated as a result of climate change (e.g. IPCC, 2007; Ekström et al., 2005; Palmer and Räisänen, 2002). Therefore, an additional leverage to accommodate such increases should be considered for the life-time of the flood defences.

Results presented here are particularly relevant to support organisations responsible for flood risk management. In England and Wales, for example, local authorities, as the designated Lead Local Flood Authority4, have the responsibility of coordinating, planning, preparing and responding to local flood risk. At locations benefiting from flood defences, flooding occurs when defences fail or are overwhelmed by extreme events exceeding the level of protection they offer. This problem is illustrated by two recent flood events that occurred in Portsmouth in September 2000 and May 2008 where, despite the presence of pumping stations the local area was flooded by extreme rainfall. On 15 September 2000, 60 $\mathrm{mm}$ of rain fell in three hours causing a failure at the pumping station in Eastney, which resulted in foul water flooding affecting 114 properties (PCC, n/a). Some properties were once again flooded with raw sewage on 26 May 2008 due to overwhelmed drains when the area received $30 \mathrm{~mm}$ of rainfall in 12 hours (The News, 27 May 2008). Southern Water reported that the pumping station was working at full capacity but simply could not cope with the volume of water (The News, 27 May 2008).

The events described above resulted in the construction of a $£ 10$ million emergency pumping station to prevent sewer flooding in Portsmouth from rainfall events of 1 in 76 year return period (Roberts and Potter, 2010). Results shown in this article indicate only a small variation between estimates of extreme rainfall for Southsea when different PDs are used. Therefore, the actual level of protection offered by the new pumping station is likely to be very close to the expected. Nevertheless, the same should not be assumed to be valid in all places. One can only hope that the capacity of new flood defences in England and elsewhere are designed taking into consideration the uncertainties of assigning one specific PD to the rainfall time-series. The high investment involved in building or upgrading flood defences warrant that robust methods of analysis are used to ascertain that the investment will provide the desired level of protection.

\section{Conclusions}

This work raises awareness of the limitations of common practices in extreme rainfall analysis by demonstrating that estimates of rainfall depths can differ significantly depending on the PD used. Although distributions traditionally used (e.g. GEV, Generalised Pareto, EV1) fit reasonably well maxima series of measured rainfall, they are not necessarily the

\footnotetext{
${ }^{4}$ A role created by the Flood and Water Management Act (implemented in October 2010).
} 
models best fitting the data. It is suggested here that the design of local defences should be based on the statistics of local rainfall data and take into consideration the range of extreme values estimated by the best-fit distributions identified by more than one test (e.g. A-D, K-S and Chi-squared). Comparing the results of rainfall depths of selected return periods estimated by the best-fit PDs according to different tests provides a measure of uncertainty. The use of dedicated and accessible software facilitates the identification of the best-fit distributions. Therefore, this is a practical and straightforward approach that can be widely applied to assess uncertainties related to extreme rainfall analysis commonly used in the design of flood defences.

As shown by the selected case studies, the sensitivity of local rainfall datasets to the application of specific PDs can vary considerably even between closely located stations exposed to similar weather patterns. For some of the maxima series analysed here, the use of different tests and distributions resulted in very similar estimates of extreme rainfall depths. Other maxima series showed variations up to $42 \%$ between the results obtained from the best-fit distributions identified by different tests, especially for return periods longer than 25 years. Similar variability can be found worldwide where local particularities affect the rainfall distribution over small areas and/or time-series of rainfall measurements are relatively short. The extra effort of using a range of models in the analysis of extreme rainfall is well justified as it can improve the assessment of the level of protection provided to people and infrastructure by the expensive investments in upgrading or building new flood defences.

\section{Acknowledgements}

This research has been conducted within the project SECOA (Solutions for Environmental Contrasts in Coastal Areas) funded by the EU Framework 7 programme (project number 244251). Measured daily rainfall datasets used in this research were kindly provided by the Met Office via the British Atmospheric Data Centre. The helpful comments of Jo Foord, Graham Walters, Jon Williams and the three anonymous reviewers that assisted in the improvement of this manuscript are greatly appreciated.

\section{References}

Adamowski, K., 2000. Regional analysis of annual maximum and partial duration data by nonparametric and L-moment methods. J. Hydrol., 229, 219-231.

Anderson, K., Darling, D. A., 1952. Asymptotic theory of certain "goodness-of-fit" criteria based on stochastic processes. Ann. Math. Stat.,23, 193-212.

Anderson, T.W., Darling, D.A., 1954. A test of goodness-of-fit. J. Am. Stat. Assoc.,49, 765-769.

Arnaud, P., Bouvier, C., Cisneros, L., Dominguez, R., 2002. Influence of rainfall spatial variability on flood prediction. J. Hydrol., 260, 216-230. 
Bodini, A., Cossu, Q.A., 2010. Vulnerability assessment of Central-East Sardinia (Italy) to extreme rainfall events. Nat. Hazards Earth Syst. Sci., 10, 61-72.

Brown, J.M., Souza, A.J., Wolf, J., 2010. An 11 -year validation of wave-surge modelling in the Irish Sea, using a nested POLCOMS-WAM modelling system. Ocean Model., 33, 118-128.

Burr, I.W., 1942. Cumulative Frequency Functions. Ann. Math. Statist., 13(2), 215-232.

Chakravarti, I., Laha, R., Roy, J., 1967. Handbook of Methods of Applied Statistics, Volume I. John Wiley \& Sons, pp. 392-394.

Coles, S., 2001. An introduction to statistical modeling of extreme values. Springer, 228p.

Cunnane, C., 1973. A particular comparison of annual maxima and partial duration series methods off lood frequency prediction. J. Hydrol., 18, 257-271.

Davidson, A.C., Smith, R. L., 1990. Models for exceedances over high thresholds. J.R. Statist. Soc. B, 52(3), 393-442.

EA (Environment Agency), 2009.Flooding in England: A national assessment of flood risk.33p. Available online from: www.publications.environment-agency.gov.uk/pdf/GEHO0609BQDS-EE.pdf.

EA (Environment Agency), 2011. Understanding the risks, empowering communities, building resilience. The national flood and coastal erosion risk management strategy for England. Environment Agency and Defra document presented to Parliament pursuant to Section 7 of the Flood and Water Management Act 2010. Available online from: www.publications.environmentagency.gov.uk/pdf/GEHO0711BTWK-E-E.pdf.

Ekström, M., Fowler, H.J., Kilsby, C.G., Jones, P.D., 2005.New estimates of future changes in extreme rainfall across the UK using regional climate model integrations.2. Future estimates and use in impact studies. J. Hydrol., 300, 234-251.

Evans, E.P., Ashley, R., Hall, J.W., Penning-Rowsell, E.C., Sayers, P.B., Thorne, C.R., Watkinson, A.R., 2004. Foresight Future Flooding. Scientific Summary: Volume 2: Managing Future Risks. Office of Science and Technology, London. 59p.

Flather, R. A., Smith, J. A., Richards, J. D., Bell, C., Blackman, D. L., 1998. Direct estimates of extreme storm surge elevations from a 40-year numerical model simulation and from observations. Glob. Atmos. Ocean Syst., 6, 165-176.

Forbes, C., Evans, M., Hastings, N., Peacock, B., 2011. Statistical distributions (4 ${ }^{\text {th }}$ ed.). John Wiley \& Sons, 212p.

IPCC, 2007. Climate Change 2007: The Physical Science Basis. Summary for Policymakers, Contribution of Working Group I to the Fourth Assessment Report of the Intergovernmental Panel on Climate Change.

Jha, A.K, Block, R., Lamond, J., 2012. Cities and Flooding: a Guide to Integrated Urban Flood Risk Management for the $21^{\text {st }}$ Century. The World Bank, Washington, 631p.

Johnson, N.L., Kotz, S., Balakrishnan, N., 1994.Continuous Univariate Distributions, Volume I ( $2^{\text {nd }}$ ed.).John Wiley \& Sons, 784p.

Klein Tank, A. M. G., Können, G. P., 2003. Trends in indices of daily temperature and precipitation extremes in Europe, 1946-99. J. Climate, 16, 3665-3680.

Koutsoyiannis, D., Baloutsos, G., 2000. Analysis of a long record of annual maximum rainfall in Athens, Greece, and design rainfall inferences. Nat. Haz., 29, 29-48.

Lowe, J. A., Gregory, J. M., 2005. The effects of climate change on storm surges around the United Kingdom. Phil. Trans. Roy. Soc., Ser. A, Math. Phys. Sci., 363, 1313-1328.

Norrant, C., Douguédroit, A., 2006. Monthly and daily precipitation trends in the Mediterranean (19502000). Theor. Appl. Climatol.,83, 89-106.

NIST/SEMATECH, 2010. e-Handbook of Statistical Methods, http://www.itl.nist.gov/div898/handbook/, last updated on 23 June 2010.

Palmer, T.N., Räisänen, J., 2002. Quantifying the risk of extreme seasonal precipitation events in a changing climate. Nature, 415,512-514. 
PCC (Portsmouth City Council), n/a. Planning to adapt to climate change - a headline summary. NI 188 - draft headline summary for services. Available online from: http://www.climatesoutheast.org.uk/images/uploads/Portsmouth_headline_summary_final.pdf, accessed on $04 / 04 / 2011$.

Pugh, D. T.,1996. Tides, Surges, and Mean Sea-Level. John Wiley \& Sons, 472p.

Roberts, C., Potter, S., 2010. Eastney storm pumping station, £20m ten-point plan to protect Portsmouth from flooding. Wastewater and Treatment \& Sewerage, p. 94-95. Available online from http://waterprojectsonline.com/case studies/2010/Southern Eastney 2010.pdf; last accessed on 30 August 2011.

Rosbjerg, D., 1977. Return periods of hydrological events. Nord. Hydrol., 8, 57-61.

Stephens, M. A., 1974. EDF Statistics for Goodness of Fit and Some Comparisons. J. Am. Stat. Assoc., 69, 730-737.

Stephens, M. A., 1977. Goodness of Fit for the Extreme Value Distribution. Biometrika, 64, 583-588.

Tadikamalla, P.R., 1980. A look at the Burr and related distributions. Int. Stat. Rev., 48, 337-344.

The News, 27 May, 2008. Heavy rainfall causes flooding. Available online from: http://www.portsmouth.co.uk/news/local/easthampshire/heavy_rainfall_causes_flooding_1_1295612, accessed on 04/04/2011.

Thurston, H.W., Taylor, M.A., Shuster, W.D., Roy, A.H., Morrison, M.A., 2010. Using a reverse auction to promote household level stormwater control. Environ. Sci. Policy, 13, 405-414.

Toretti, A., Xoplaki, E., Maraun, D., Kuglitsch, F.G., Wanner, H., Luterbacher, J.,2010. Characterisation of extreme winter precipitation in Mediterranean coastal sites and associated anomalous atmospheric circulation patterns. Nat. Hazards Earth Syst. Sci., 10, 1037-1050.

UNISDR, 2011. Revealing Risk, Redefining Development: Summary and Main Findings. United Nations Global Assessment Report on Disaster Risk Reduction, 20 p. Available online from: http://www.undp.org.bd/info/pub/GAR\%20Exe\%20Summary.pdf, last accessed on 15 October 2012.

Verlaan, M., Zijderveld, A., de Vries, H., Kroos, J., 2005. Operational storm surge forecasting in the Netherlands: developments in the last decade. Phil. Trans. R. Soc. A, 363, 1441-1453.

Wang, S., McGrath, R., Hanafin, J. A., Lynch, P., Semmler, T., and Nolan, P., 2008. The impact of climate change on storm surges over Irish waters. Ocean Model., 25, 83-94.

White, I., Howe, J., 2002. Flooding and the role of planning in England and Wales: a critical review. J. Environ. Plann. Man., 45(5), 735-745.

Wheater, H., Evans, E., 2009. Land use, water management and future flood risk. Land Use Policy, 265, S251-264. 
Appendix A: Parameter values for the Burr and best fit distributions according to K-S and A-D tests for the AMS datasets.

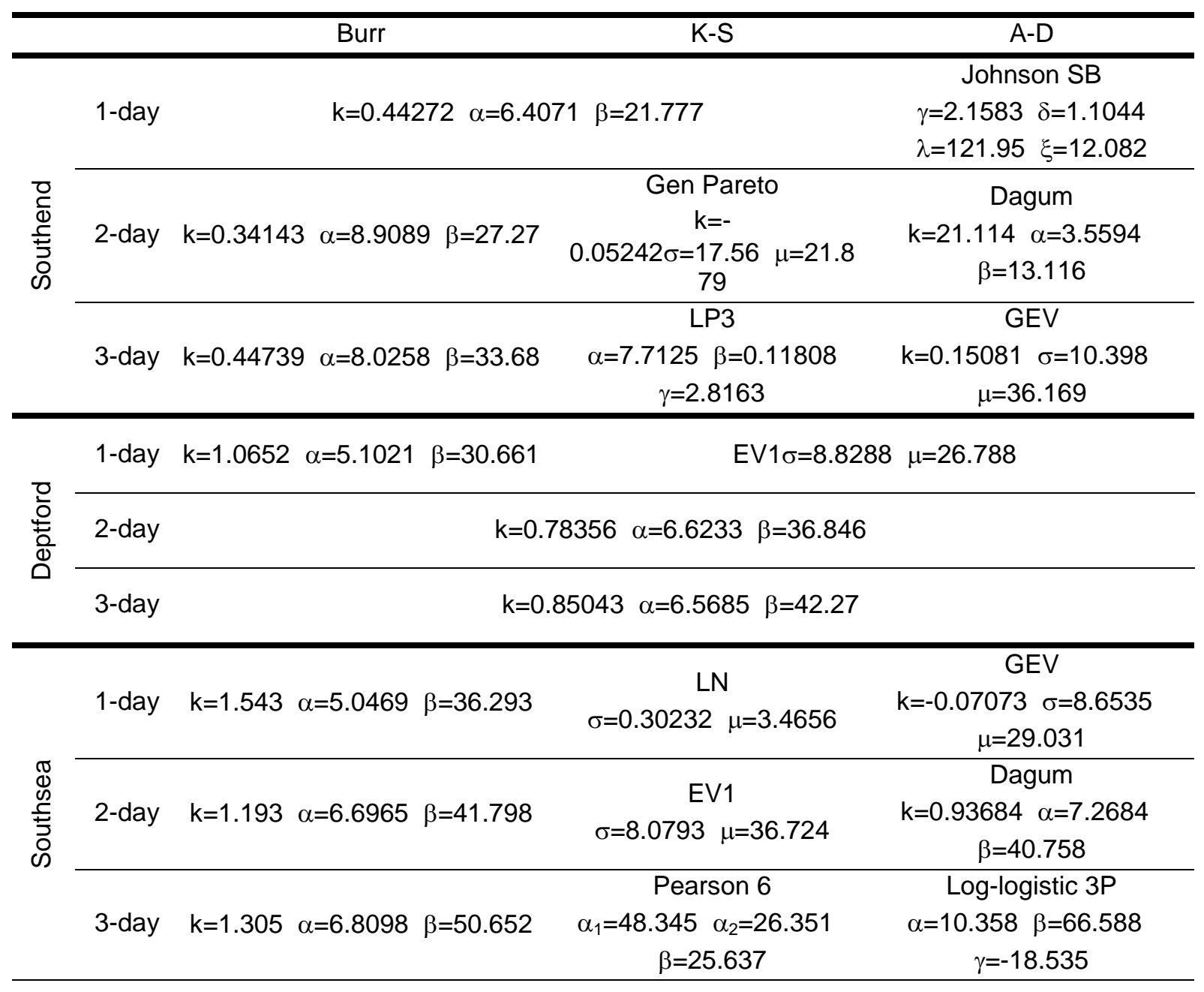


Appendix B: Precipitation depths $(\mathrm{mm})$ for selected return periods (years) based on the Burr and best fit-distributions for Southend, Deptford and Southsea.

\begin{tabular}{|c|c|c|c|c|c|c|c|}
\hline \multicolumn{8}{|c|}{ Southend } \\
\hline \multicolumn{2}{|c|}{ Return periods (yrs) } & 5 & 10 & 25 & 50 & 100 & Distribution \\
\hline \multirow{8}{*}{ AMS } & \multirow[b]{2}{*}{ 1-day } & 38.25 & 49.00 & 67.73 & 86.48 & 110.43 & Burr \\
\hline & & 40.48 & 50.05 & 61.93 & 70.17 & 77.69 & Jonhson SB \\
\hline & \multirow{3}{*}{ 2-day } & 46.24 & 58.13 & 78.57 & 98.68 & 123.93 & Burr \\
\hline & & 48.98 & 59.97 & 73.89 & 83.99 & 93.72 & Gen Pareto \\
\hline & & 47.02 & 58.10 & 75.87 & 92.46 & 112.50 & Dagum \\
\hline & \multirow{3}{*}{ 3-day } & 52.55 & 63.91 & 82.54 & 100.12 & 121.44 & Burr \\
\hline & & 53.81 & 64.35 & 79.33 & 91.77 & 105.36 & LP3 \\
\hline & & 53.67 & 64.03 & 78.91 & 91.41 & 105.20 & GEV \\
\hline \multirow{4}{*}{ WMS } & 1-day & 18.94 & 24.83 & 35.29 & 45.98 & 59.90 & Burr \\
\hline & 2-day & 24.17 & 30.69 & 41.23 & 51.26 & 63.62 & Burr \\
\hline & \multirow{2}{*}{ 3-day } & 29.50 & 36.90 & 46.75 & 54.27 & 61.85 & Burr \\
\hline & & 29.47 & 37.46 & 50.16 & 62.08 & 76.63 & Log-Logistic 3P \\
\hline \multirow{9}{*}{ SMS } & \multirow{3}{*}{ 1-day } & 28.44 & 35.67 & 46.91 & 57.25 & 69.67 & Burr \\
\hline & & 28.56 & 36.11 & 48.08 & 59.29 & 72.96 & Log-Logistic 3P \\
\hline & & 28.45 & 35.70 & 47.00 & 57.42 & 69.93 & Dagum \\
\hline & \multirow{3}{*}{ 2-day } & 33. 79 & 42.34 & 55.90 & 68.58 & 83.97 & Burr \\
\hline & & 34.76 & 43.75 & 56.50 & 67.05 & 78.52 & Log-Gamma \\
\hline & & 34.04 & 42.83 & 56.83 & 70.00 & 86.12 & Log-Logistic 3P \\
\hline & \multirow{3}{*}{ 3-day } & 39.64 & 48.50 & 61.19 & 72.07 & 84.43 & Burr \\
\hline & & 40.59 & 49.82 & 61.01 & 68.94 & 76.54 & Weibull 3P \\
\hline & & 40.06 & 48.98 & 60.31 & 68.71 & 77.01 & Fatigue Life \\
\hline
\end{tabular}

\begin{tabular}{|c|c|c|c|c|c|c|c|}
\hline \multicolumn{8}{|c|}{ Deptford } \\
\hline Returr & period (yrs) & 5 & 10 & 25 & 50 & 100 & Distribution \\
\hline \multirow{4}{*}{ AMS } & \multirow[t]{2}{*}{ 1-day } & 39.95 & 46.40 & 54.62 & 60.89 & 67.35 & Burr \\
\hline & & 40.03 & 46.66 & 55.03 & 61.24 & 67.40 & EV1 \\
\hline & 2-day & 49.21 & 56.95 & 68.34 & 78.22 & 89.45 & Burr \\
\hline & 3-day & 55.00 & 63.17 & 74.95 & 85.02 & 96.33 & Burr \\
\hline \multirow{8}{*}{ WMS } & \multirow{3}{*}{ 1-day } & 20.32 & 24.43 & 30.54 & 35.93 & 42.18 & Burr \\
\hline & & 21.25 & 25.65 & 31.16 & 35.20 & 39.15 & Erlang (3P) \\
\hline & & 21.20 & 25.46 & 30.28 & 33.36 & 36.01 & Johnson SB \\
\hline & \multirow{3}{*}{ 2-day } & 25.88 & 30.23 & 36.30 & 41.37 & 47.01 & Burr \\
\hline & & 27.20 & 30.57 & 34.16 & 36.49 & 38.57 & Normal \\
\hline & & 26.38 & 30.90 & 36.48 & 40.55 & 44.52 & Inv. Gaussian \\
\hline & \multirow{2}{*}{ 3-day } & 31.69 & 37.25 & 44.87 & 51.14 & 58.02 & Burr \\
\hline & & 32.20 & 38.04 & 45.36 & 50.76 & 56.08 & GEV \\
\hline \multirow{7}{*}{ SMS } & \multirow{3}{*}{ 1-day } & 30.74 & 37.12 & 46.14 & 53.79 & 62.39 & Burr \\
\hline & & 32.69 & 39.05 & 45.80 & 49.95 & 53.46 & Pert \\
\hline & & 31.78 & 38.38 & 46.05 & 51.18 & 55.79 & Johnson SB \\
\hline & \multirow[t]{2}{*}{ 2-day } & 37.65 & 44.52 & 53.37 & 60.24 & 67.45 & Burr \\
\hline & & 37.94 & 45.30 & 54.42 & 61.06 & 67.55 & GEV \\
\hline & \multirow[b]{2}{*}{ 3-day } & 42.92 & 49.22 & 56.27 & 61.03 & 65.48 & Burr \\
\hline & & 42.23 & 48.61 & 57.00 & 63.80 & 71.20 & Dagum \\
\hline
\end{tabular}




\begin{tabular}{|c|c|c|c|c|c|c|c|}
\hline \multicolumn{8}{|c|}{ Southsea } \\
\hline \multicolumn{2}{|c|}{ Return period (yrs) } & 5 & 10 & 25 & 50 & 100 & Distribution \\
\hline \multirow{9}{*}{ AMS } & \multirow{3}{*}{ 1-day } & 40.94 & 46.38 & 53.45 & 59.00 & 64.89 & Burr \\
\hline & & 41.27 & 47.14 & 54.32 & 59.53 & 64.64 & LN \\
\hline & & 41.35 & 47.03 & 53.80 & 58.54 & 63.01 & GEV \\
\hline & \multirow{3}{*}{ 2-day } & 48.88 & 54.47 & 61.89 & 67.81 & 74.15 & Burr \\
\hline & & 48.84 & 54.90 & 62.57 & 68.25 & 73.89 & EV1 \\
\hline & & 48.83 & 54.62 & 62.53 & 68.99 & 76.01 & Dagum \\
\hline & \multirow{3}{*}{ 3-day } & 57.72 & 63.85 & 71.82 & 78.08 & 84.68 & Burr \\
\hline & & 58.18 & 64.95 & 73.18 & 79.12 & 84.95 & Pearson 6 \\
\hline & & 57.59 & 63.79 & 71.96 & 78.42 & 85.23 & Log-Logistic 3P \\
\hline \multirow{8}{*}{ WMS } & \multirow{3}{*}{ 1-day } & 28.51 & 33.50 & 40.57 & 46.55 & 53.26 & Burr \\
\hline & & 29.21 & 34.15 & 40.19 & 44.53 & 48.75 & Fatigue Life 3P \\
\hline & & 28.75 & 33.69 & 40.36 & 45.77 & 51.65 & Burr 4P \\
\hline & \multirow{3}{*}{ 2-day } & 39.58 & 44.10 & 48.93 & 52.06 & 54.89 & Burr \\
\hline & & 39.46 & 43.92 & 48.54 & 51.46 & 54.03 & Weibull \\
\hline & & 39.84 & 44.52 & 49.25 & 52.11 & 54.51 & LP3 \\
\hline & \multirow{2}{*}{ 3-day } & 48.27 & 53.17 & 58.22 & 61.39 & 64.18 & Burr \\
\hline & & 48.31 & 53.75 & 59.37 & 62.79 & 65.66 & GEV \\
\hline \multirow{6}{*}{ SMS } & \multirow[t]{2}{*}{ 1-day } & 31.94 & 38.19 & 46.98 & 54.39 & 62.69 & Burr \\
\hline & & 31.83 & 38.30 & 47.83 & 56.18 & 65.83 & Dagum \\
\hline & \multirow[t]{2}{*}{ 2-day } & 38.59 & 44.97 & 53.24 & 59.72 & 66.57 & Burr \\
\hline & & 38.08 & 44.26 & 52.79 & 59.89 & 67.78 & Dagum \\
\hline & \multirow{2}{*}{ 3-day } & 43.52 & 50.14 & 58.05 & 63.79 & 69.47 & Burr \\
\hline & & 43.01 & 49.47 & 58.08 & 65.09 & 72.74 & Dagum \\
\hline
\end{tabular}

